\title{
Is There a Feedback Mechanism in Accounting?
}

\author{
Krzysztof Drachal
}

\section{Introduction}

Accounting information system is a specific methodology of collecting, storing and processing financial data in a given organization (Romney, Steinbart, 2003). Of course, currently such systems are heavily computer-based, both because of rapid decrease in electronic device prices and increase in their abilities to store large amount of data, but also due to the amount of data that any organization is faced up with every day on the market. It is not without a reason that sociologists have coined terms like "information age" or "information society" to describe modern times (Beniger, 1986; Castells, 2000).

Therefore one can expect some pressure on managers to make decision in such a way that they would look impressively in the system. As a result the style of management can depend on the particular system. In other words, the accounting information system can somehow shape management style through the feedback mechanism. Such a hypothesis is discussed further in the text.

The feedback mechanism is understood by means that people react upon the information conveyed by accounting. Therefore managers can become motivated to act in a way to produce specific data, which becoming a piece of information, would influence people's reaction. The aim of this paper is to critically review some points of view on this topic, found in the literature. There are various methods that can be applied to study the presented problem and, as it will be shown later in the text, there is no consensus on the existence of the opportunistic behavior. Therefore it is reasonable to present some moderately short discussion based on selected literature.

Krzysztof Drachal; Faculty of Mathematics and Information Science, Warsaw University of Technology, <K.Drachal@ mini.pw.edu.pl>. 


\section{Debate}

If the past ages were dominated by the heavy industry and were highly orientated on the production of material goods, in the current period it is the information, which is a precious good by itself. Of course, information has always been very important on the market. But the ratio of information to material assets in an efficient organization has changed rapidly. Please notice, that in developed economies the percentage of production workers in total employment has declined since 1900. On the other hand, professional creative workers (e.g. engineers, scientists, planners, artists, etc.) are becoming more numerous in the modern economy than they used to be in the 20th century (Nakamura, 2000).

For example, Stiglitz (2002) emphasized that modern economy is biased by a new paradigm. It is the importance of the information. On the other hand, due to the increasing transparency of the economy, initiated by dynamical development of electronic media, the term "nude economy" is also used by some scientists. But are there not any dark sides of these changes? Surely, if something goes wrong, then the gossip can spread in a very quick time. But there is still a problem with "asymmetry of information". Moreover, because of huge data available, the problem by itself is to decide which of these data should be analyzed.

If considering dark sides of information processing in the field of accounting, the term "creative accounting" is usually used. It is not well known, when exactly this term has been coined. But, doubtlessly, it became very popular in 2000s when a lot of accounting irregularities were reported on United States market, and when the serious market downturn occurred.

Some managers had spotted not only (which is quite obvious) that people study financial information before investing money in stocks, projects, etc., but they had also spotted that it is really worth to manage these information in such a way that they would look better than it really is. Sometimes such actions may be legal and even a bit reasonable. For example, if company has little income in current year and, moreover, has to buy something near the year-end in order to gain profits in the coming year. Then it may be more reasonable to deal with delivers that bills will be issued and goods will be delivered not in December but in January. As a result costs will be accounted in the next year, when also the profits are expected. Unfortunately, in companies like Tyco Int., MCI Inc. and 
(probably the most known one) Enron, such actions were exaggerated and become simple accounting frauds instead of dynamical management. It was not an adjusting; it was booking false or fictitious records. The fact that some of these actions were done with a collaboration with Arthur Andersen resulted in shrinking so called Big-5 to Big-4. Losing the reputation forced such a large corporation as Arthur Andersen to collapse.

As a result, Sarbanes-Oxley Act of 2002 has been signed by George W. Bush to prevent from such actions in the future in the United States. This way the proper usage of accounting information systems became much more controlled by law. Similar law regulations were enacted also in other developed countries (Farell, 2005). But one should also keep in mind the spectacular fall of over 200 year-old Barings Bank, which was the result of too much risk level accepted by just one of their managers (Drummond, 2007). Also recently investors mistook coming IPO of Twitter with the bankrupt Twitter Home. This example shows that in every system a human may be the most fragile part of it (Mikolajczak, 2013). Therefore accountants should not solely rely on laws and systems, because they may be illusive.

The above examples illustrate quite obvious fact that organizations have to shape their accounting information systems in order to keep them suitable for actual market. But one may also ask whether this relationship is a two-way one, i.e. whether organizations are also shaped by their accounting information systems.

The first answer can state that the whole systems are changed after such spectacular events happen. In different years managers and auditors focus on other topics - these that are currently on the spot. But there may also be some deeper relationships.

For example, Ezzamel and Bourn (1990) asked what is the role of the discussed systems when dealing with financial crisis. They found that the advantage of any well working system is its ability to quickly collect and process all-important data. The second important factor is that the good system must produce understandable numbers. Managers have to know what the numbers exactly mean. They should also be comparable in a sense that numbers from different periods and situations should give a meaning to what has changed. Ezzamel and Bourn (1990) were working on quite specific organization. Therefore they found that if managers are expected to rely on accounting information systems, these systems have 
to be tailored to the particular organization, with a consistency to its organizations culture, mission and vision. Otherwise, managers would not rely on the outcome of the system. It would be treated just as some obligatory work, but which is useless in real life.

Ezzamel and Bourn (1990) also observed that in periods of low market uncertainty, the discussed systems are not very interesting to managers, but with increasing market risk, managers tend to stick to them as the only reliable sources of information. Hopwood (2009) also argued that in case of crisis organizations put more attention on accounting information. The process of data collection then becomes more detailed and intensive.

But according to Subramanyam (1996) the opportunism in accounting choice is not a prevailing practice. Moreover, Lambert (2001) stated that the managers are motivated to act honestly to overcome some disadvantages from agency contracts under information asymmetry. However, the approach towards different type of information (mandatory one, voluntary disclosure, etc.) can differ in various cultures. An example from exotic market is given by Hassan and Power (2009). Despite the arguments of Subramanyam (1996), the occurrence of managerial opportunism is supported by findings of Boubakri, Ghalleb and Boyer (2008).

The systematic classification of different cultural aspects for different countries in the context of management has been started by Hofstede (1980). It was also hypothesized then that some cultural aspects may affect financial disclosures. Jaggi and Low (2000) found that, for example, financial disclosures are higher in common law countries than in code law countries. These are also vivid problems. For example, when General Electric led a dynamic expansion on Western European markets in 1990s, it forced its model of accounting and management despite the fact that Europeans had significant objections towards the American business model (Taras et al., 2011).

Hines (1998) observed that, indeed, actions in organization are based on accounting information. But the greater importance is which data are taken out of large data available from the world. From the vast amount of facts and figures, only some of them are evidenced. This is actually a common and obvious fact about collecting data. Of course, the real market is constituted by enormous amount of interactions. But only finite 
number of them is measured and presented to a decision maker. At least, it is impossible to number and measure all available data. Always, some of them have to be chosen as the important ones and some have to be omitted. Therefore the decision maker acts on the base of some chosen data. But choosing different data may change the picture of real market situation. Sometimes - even drastically.

Bayou, Reinstein and Williams (2011) considered the problem between usefulness and the truth in accounting objectives. They argued that these values are in conflict, in general. They suggested that the role of accountants in the democratic society is currently "too narrowly constructed". Therefore there emerges a problem of objectivity in accounting. In other words, one would like to know whether any process of accounting could be really objective in principle. McKernan (2007) provided detailed analysis and concluded that such a process is possible indeed.

On the other hand, using more shocking words, Morgan (1988) concluded that "objectivity in accounting is largely a myth". It is always some kind of dialogue with reality. Accountants "construct, read and probe situations in a variety of ways". In case of any accounting information system there is a temptation to use the above fact in unfair way, i.e. not only to use the picture to judge actions, but act in a way that the system approves. Even if it would not be reasonable by the common sense.

In the notes to her article Hines (1998) presents some comparison of quantum and classical physics, which may sound too emphatic or misty for non-specialist. Her opinion may also be restated in (probably more friendly for non-physicist) analogy to different branches of mathematics: algebra and geometry. In algebra one works with abstract numbers. Sticking to fixed rules from a given set of numbers one is able to produce another number by some operations (abstract, but clearly defined rules). On the other hand, in geometry one works with pictures (or sketches, which are not clearly defined). Of course, the rules are also based on logic, but in geometry one is not just putting numbers into a machine, but uses own intuition. Except logic one also uses an unclear general picture of whole situation. Similarly, like the left and the right brain hemisphere. In order to produce efficient outcome, both of them should cooperate. The moral may be that managers should use their intuition when interpreting outcomes of any accounting information system. 
On the other hand, Kothari (2001) extensively reviewed the interactions of capital markets and accounting. As a result, it was concluded that there are plenty of sources of information, and accounting is not the only one. Also Lee (2001) stated that the influence of accounting information is not trivial or instantaneous.

For the discussion on the decision usefulness of information one should also see, for example, Beaver (2002) and Hjelstrom, Hjelstrom and Sjogren (2014). Indeed, there are strong arguments that market efficiency is present even during the periods of crisis (Gajdosova - Heryna - Tufan, 2011; Heryan - Stavarek, 2012). For example, Prochazka (2011) discussed the very important role of fair value measurement in the recent financial crisis. According to Imhoff (2003) one should perceive the accounting rather as a continuous process of extracting information from raw data, where the good receipts change from time to time.

Also Bushman and Smith (2001) discussed contracting and accounting information. They discussed the role of the accounting information in the governance processes. Armstrong, Guay and Weber (2010) noticed the possible conflicts between managers, directors and shareholder. Therefore they emphasized the role of transparency in financial reporting.

Hopwood (2009) emphasized that information in accounting should not be processed without any reflection. It must be controlled and the methodology should be adequate to the current market situation. For example, the notion of "fair value" is quite flexible. Therefore its valuation should be done with extreme responsibility of the accountant. Using the analogy given previously: intuition should control whether fixed rules are applicable and suitable for the organization and market. Whereas rules themselves should not allow the intuition of a manager to undertake too much risk or to act without any rules at all or too spontaneously.

It is also argued by Hopwood (2009) that it is not only important what profit is obtained in a sense of numbers, but also how this profit is obtained in the organization. Except sole numbers, their transparency is becoming extremely important. It is especially in the context of recent financial crisis. 
On the other hand, Kotb, Roberts and Sian (2012) put much stress on new technologies. They argued that auditor could not rely on classical knowledge from accounting if working for e-commerce. High level of technical knowledge is additionally needed in order to really understand what is going on. Such businesses are becoming more and more important part of market. Therefore it is expected that they will seriously impact basic skills needed by auditor or accountant in modern organization. Auditor should have a proper understanding of processes going on in the organization. He or she cannot possess just basic skills from finances and law. It is emphasized that currently there are few such specialists. Moreover, IT specialists and business or financial specialists do not understand each other. If auditors want to survive, they have to adapt to the new situation.

Finally, one has to consider the impact of globalization. Even small organizations usually have to consider global market or at least cooperation with multinational organizations. Therefore accounting information system has to consider global system. For accountants it means that they should be qualified at the global (not only local) level. For example, they have to understand international differences in law, even if some accounting international standards are already known (Sabau - Ionescu - Stanciu, 2012). They must continuously increase their skills with great stress on new technologies and e-processes in organizations.

\section{Conclusion}

It should be concluded that accounting practices have to be based on strong ethical rules. The ethical problems become more and more important, especially in the context of the huge increase of available data and possibility to store and process such data in modern organizations.

Managers and accountants should be extremely cautious towards the data. Mechanical processing can be biased by disadvantages of accounting information systems and unreflective methodologies can lead to serious problems. The great advantage of any accounting information system, which is allowing an accountant not to track every transaction, can also be the great disadvantage. The intuition plays a great role then.

The fact that accounting information is perceived differently in various stages of business cycle implies that enough big attention should 
be put on that information all the time. It can be achieved, for example by proper trainings of the staff, etc.

The problem of the existence of a feedback mechanism between accounting information system and managers is present. Unfortunately, it can lead to some pathology. Therefore it is important to develop other mechanisms, which would diminish the possible disadvantages.

\section{References}

Armstrong, C.S. - Guay, W.R. - Weber, J.P. (2010): The Role of Information and Financial Reporting in Corporate Governance and Debt Contracting. Journal of Accounting and Economics, 2010, vol. 50, no. 23, pp. 179-234.

Bayou, M.E. - Reinstein, A. - Williams, P.F. (2011): To tell the truth: A discussion of issues concerning truth and ethics in accounting. Accounting, Organizations and Society, 2011, vol. 36, no. 2, pp. 109-124.

Beaver, W.H. (2002): Perspectives on Recent Capital Market Research. The Accounting Review, 2002, vol. 77, no. 2, pp. 453-474.

Beniger, J.R. (1986): The Control Revolution: Technological and Economic Origins of the Information Society. Cambridge MA, Harvard University Press, 1986.

Boubakri, N. - Ghalleb, N. - Boyer, M.M. (2008): Managerial Opportunism in Accounting Choice: Evidence from Directors' and Officers' Liability Insurance Purchases. SSRN Paper, no. 1109254.

Bushman, R.M. - Smith, A.J. (2001): Financial Accounting Information and Corporate Governance. Journal of Accounting and Economics, 2001, vol. 32, no. 1-3, pp. 237-333.

Castells, M. (2000): The Rise of the Network Society. Malden MA, Blackwell, 2000.

Drummond, H. (2007): The Dynamics of Organizational Collapse. London, Routledge, 2007.

Ezzamel, M. - Bourn, M. (1990): The Roles of Accounting Information Systems in an Organization Experiencing Financial Crisis. Accounting. Organizations and Society, 1990, vol. 15, no. 5, pp. 399-424.

Farell, G. (2005): America Robbed Blind. Austin TX, Wizard Academy Press, 2005. 
Gajdosova, K. - Heryan, T. - Tufan E. (2011): Day of the week effect in the European emerging stock markets: recent evidence from the financial crisis period. Scientific Papers of the University of Pardubice, 2011, vol. 19 , no. 1, pp. 38-51.

Hassan, O. - Power, D.M. (2009): The usefulness of accounting information; evidence from the Egyptian market. Qualitative Research in Financial Markets, 2009, vol. 1, no. 3, pp. 125-141.

Heryan, T. - Stavarek D. (2012): Day of the week effect in Central European stock markets. MPRA, 2012, Paper no. 38431.

Hjelstrom A. - Hjelstrom, T. - Sjogren, E. (2014): Decission usefulness explored: An investigation of capital market actors' use of financial reports. Stockholm, Svenskt Naringsliv, 2014.

Hopwood, A.G. (2009): The economic crisis and accounting: Implications for the research community. Accounting, Organizations and Society, 2009, vol. 34, no. 6-7, pp. 797-802.

Imhoff E.A. (2003): Accounting quality, auditing, and corporate governance. Accounting Horizons, 2003, vol. 17, no. 1, pp. 117-128.

Jaggi, B. - Low, P.Y. (2000): Impact of Culture, Market Forces, and Legal System on Financial Disclosures. International Journal of Accounting, 2000, vol. 35, no. 4, pp. 495-519.

Kotb, A. - Roberts, C. - Sian, S. (2012): E-Business Audit: Advisory Jurisdiction or Occupational Invasion? Critical Perspectives on Accounting, 2012, vol. 23, no. 6, pp. 468-482.

Kothari, S.P. (2001): Capital Market Research in Accounting. Journal of Accounting and Economics, 2001, vol. 31, no. 1-3, pp. 105-231.

Lambert, R.A. (2001): Contracting Theory and Accounting. Journal of Accounting and Economics, 2001, vol. 32, no. 1-3, pp. 3-87.

Lee, C.M.C. (2001): Market Efficiency and Accounting Research: A Discussion of "Capital Market Research in Accounting” by S.P. Kothari. Journal of Accounting and Economics, 2001, vol. 31, no. 1-3, pp. 233253.

McKernan, J.F. (2007): Objectivity in accounting. Accounting, Organizations and Society, 2007, vol. 32, no. 1-2, pp. 155-180.

Mikolajczak, C. (2013): Tweeter Home shares explode on apparent Twitter mix-up. [on-line], Reuters, New York, [cited 25 ${ }^{\text {th }}$ November 
2014], <http://www.reuters.com/article/2013/10/04/us-tweeterhometwitter-idUSBRE9930P220131004>

Morgan, G. (1988): Accounting as reality construction: Towards a new epistemology for accounting practice. Accounting, Organizations and Society, 1998, vol. 13, no. 5, pp. 477-485.

Nakamura, L.I. (2000): Economics and the New Economy: The Invisible Hand Meets Creative Destruction. Business Review, vol. 2000, no. July/August, pp. 15-30.

Prochazka, D. (2011): The Role of Fair Value Measurement in the Recent Financial Crunch. Prague Economic Papers, vol. 2011, no. 1, pp. 71-88.

Romney, M.B. - Steinbart, P.J. (2003): Accounting Information Systems. New Jersey, Prentice Hall, 2003.

Sabau, G. - Ionescu, D. - Stanciu, J.A. (2012): Financial accounting information global system in change management. Sibiu Alma Mater University Journals. Series A: Economic Sciences, 2012, vol. 5, no. 1, pp. 46-49.

Stiglitz, J.E. (2002): Information and the Change in the Paradigm in Economics. American Economic Review, 2002, vol. 92, no. 3, pp. 460501.

Subramanyam, K.R. (1996): The Pricing of Discretionary Accruals. Journal of Accounting and Economics, 1996, vol. 22, no. 1-3, pp. 249281.

Taras, V. - Steel, P. - Kirkman, B.L. (2011): Three decades of research on national culture in the workplace: Do the differences still make a difference?. Organizational Dynamics, 2011, vol. 40, no. 3, pp. 189-198. 


\title{
Is There a Feedback Mechanism in Accounting?
}

\begin{abstract}
The aim of this paper is to present some considerations about the (market) reality and the accounting. The considerations are some kind of a discussion, how accounting systems are linked by the feedback mechanism with managers. Various aspects of modern markets are presented. In particular, the role of globalization processes, increasing role of financial institutions and role of information are discussed. It is argued that the accounting becomes more interdisciplinary topic and some skills from new technologies become a must on modern markets. The discussion is illustrated by some particular examples. It is argued that there is a strong feedback mechanism between managers and accounting information systems.
\end{abstract}

Key words: Accounting information system; Accounting standards; Creative accounting; Information in accounting; Objectivity in accounting.

JEL classification: M41, M10 